\title{
A Bayesian Best-Worst Method-Based Multicriteria Competence Analysis of Crowdsourcing Delivery Personnel
}

\author{
Longxiao Li $\mathbb{D},,^{1,2}$ Xu Wang $\mathbb{D}^{1}{ }^{1}$ and Jafar Rezaei $\mathbb{D}^{2}$ \\ ${ }^{1}$ College of Mechanical Engineering, Chongqing University, Chongqing 400030, China \\ ${ }^{2}$ Faculty of Technology, Policy and Management, Delft University of Technology, Delft 2628 BX, Netherlands \\ Correspondence should be addressed to Xu Wang; wx921@163.com
}

Received 30 July 2020; Revised 22 September 2020; Accepted 30 September 2020; Published 17 October 2020

Academic Editor: Thiago Christiano Silva

Copyright (c) 2020 Longxiao Li et al. This is an open access article distributed under the Creative Commons Attribution License, which permits unrestricted use, distribution, and reproduction in any medium, provided the original work is properly cited.

Crowdsourcing delivery is becoming a prevalent tool for tackling delivery problems by building a large labor-intensive service network. In this network, the delivery personnel consist of a large number of people with a complex composition and high level of mobility, creating enormous challenges for the quality of service and the management of a crowdsourcing platform. Hence, we attempt to conduct a competence analysis to determine whether they can provide promised services with high quality, i.e., they are competent for their job. To this end, the competence theory is introduced, and a multicriteria competence analysis (MCCA) approach is developed. To illustrate the MCCA approach, a real-world case study is conducted involving a Chinese takeaway delivery platform, where the Bayesian best-worst method is used to determine the weights of the criteria based on the data collected from managers of the platform company. Also, the competence scores of the personnel involved are collected through surveys and data sources of the company. Given the weights and the competence scores, we use additive value function to identify the overall competence scores of them, which reflects the level of competence for their job. The results show that Skills is the most important competence, while Knowledge is the least important of the four competence dimensions. In subcriteria, four core elements are identified such as punctuality, customer service awareness, responsible, and goods intact. In addition to the importance of criteria, a ranking of a sample of personnel is provided, and almost half of the crowdsourcing delivery personnel's competence is below the average and vary significantly, while the relationship between the competence level and some other variables is also discussed. Moreover, the developed MCCA approach in this paper can be applied to analyze the competence of personnel in many other industries as well.

\section{Introduction}

The prosperity of E-commerce and omnichannel retail stimulates the surge of individual packages and delivery vehicles [1] and brings great challenges to logistics operation. With the rise of the sharing economy and crowdsourcing, it is possible to reconstruct logistics operation scenarios [2]. Crowdsourcing delivery, as a successful combination of traditional logistics activities and innovative crowd resources sharing, is becoming a prevalent tool in practice. More possibilities for solving delivery problems have been provided by using the resources of the crowds [3] including maximizing crowds' utility [4], reducing infrastructure expenses, enhancing efficiency in parcel turnaround time and failure rate [5], and optimizing loading capacity [6], as well as reducing traffic congestions and pollution using spare capacity $[7,8]$.

Crowdsourcing delivery plays an increasingly important role in the logistics sector, and the crowdsourcing delivery personnel are an important link between the crowdsourcing platform and the end customers. Crowdsourcing delivery platforms embrace a large number of public and distributed delivery resources and build a complex labor-intensive service network to meet customer requests [9]. In this case, the resources involved are utilized optimally by the crowdsourcing platform. Despite the certain benefits it brings to the platform and customer, this kind of delivery also may prove precarious, since the people making up the 
crowds are with a complex composition and previously unknown [10]. Even so, the crowdsourcing platform has lowered the entry barrier and simplified registration procedures to encourage users to register [11]. Also, there are potential risks, such as package damage, loss, and privacy violations, which may affect the level of service quality and subsequently customer satisfaction and end up jeopardizing the reputation of the platform $[9,12]$. Moreover, most of the crowdsourcing delivery personnel only work part-time and usually flexibly manage their schedules [11]. Accordingly, their availability, service awareness, and service level for upcoming orders are less clear, creating the uncertainty concerning the operation process [13], which may, in turn, affect the platform's steady operation.

For the crowdsourcing delivery personnel, providing services with promised quality is a concrete manifestation of competence. The importance of them being competent and then achieving predetermined outcomes in their professionals is beyond doubt [14] that they are competent for the crowdsourcing delivery job is a critical factor when it comes to sustaining the platform's health [11]. As such, we attempt to connect the competence analysis to the new environment of crowdsourcing delivery since it provides a way to determine whether individuals meet the specified performance criteria, that is, whether they demonstrate the professional competence required [15].

Looking at the practical operations, we find that some crowdsourcing delivery platforms have made endeavors to boost the performance of the crowdsourcing delivery personnel. According to our survey, some crowdsourcing delivery platforms in China release the rider ranking and offer monetary (cash) or nonmonetary (level up) incentives based on the ranking. However, this ranking is not set for each individual, and people below a certain level are excluded. Besides, it is also simplistic to considering only the number of orders being delivered, punctuality, and platform score, as well as a certain period. Some other factors that may affect personnel's competence are not taken into account, such as the necessary skills and knowledge [16], certain work experience [17], strong customer service awareness [9], average delivery time [18], guaranteed goods condition [12], effective customer feedback [19], and innate individual traits [20]. It shows that not enough attention has been paid by practitioners to those aspects, and, as yet, a comprehensive competence analysis of crowdsourcing delivery personnel is still lacking.

Consequently, both the theoretical backgrounds and practical operations motivate us to conduct a comprehensive competence analysis of crowdsourcing delivery personnel, which is the main contribution of this study. To this end, the competence theory is introduced, and on this basis, we develop a multicriteria competence analysis (MCCA) approach, which is the generic framework and also another contribution of this study. To further illustrate the proposed MCCA approach, a real-world case study is conducted involving a Chinese takeaway delivery platform, where we use the Bayesian best-worst method to identify the weights of criteria, and the key elements contributing to crowdsourcing delivery personnel's competence are identified as well.
Combining the acquired weights and collected data, we use the additive value function to calculate the overall competence scores of the crowdsourcing delivery personnel.

The remainder of the paper is organized as follows. Section 2 provides an overview of the literature on crowdsourcing delivery and competence analysis. The developed MCCA methodology and the Bayesian BWM is presented in Section 3. Section 4 contains a real-world case study where a Chinese takeaway delivery platform is involved. In Section 5, we analyze the weights of criteria and the ranking of a sample of personnel and discuss the results of the MCCA involving crowdsourcing delivery personnel. Finally, the conclusions and suggestions for future research are provided in Section 6.

\section{Related Works}

2.1. Crowdsourcing Delivery. Crowdsourcing is a shift of work patterns that the work normally performed by designated agents is outsourced to an undefined and large pool of people with an open structure [10]. Currently, it is gaining increasing popularity, and different types of online crowdsourcing platforms have emerged such as Didi Chuxing and Uber (transport), iStockPhoto (picture), Amazon Mechanical Turk (online staffing), Threadless (apparel design), and UberEATS, Meituan takeaway, and Ele.me (online food delivery). In the crowdsourcing environment, their functions are fully tapped for consumer engagement, value acquisition, and information gathering, as well as idea generation [12].

The integration of traditional logistical activities with the concept of crowdsourcing has given rise to the concept of "crowdsourcing logistics." In addition to the term "crowd logistics," other terms, like "crowdsourcing delivery," "crowd shipping," "cargo hitching," and "collaborative logistics" are also used. In this paper, we use the term "crowdsourcing delivery." It is defined as an information network-empowered center that coordinates logistics service demand with the supply of crowd resources with free time or space and a willingness to provide the necessary services and be compensated accordingly [21]. To illustrate the concept, we use the Meituan takeaway delivery as an example and divide the entire process into seven phases: (i) a customer initiates an order request to the platform and pays; (ii) the platform releases the order online; (iii) the registered crowdsourcing delivery person receives the order; (iv) the crowdsourcing delivery person goes to the merchant to wait for the order to be prepared and then picks the order up; (v) the crowdsourcing delivery person delivers the order to the customer and clicks "Takeaway delivered" on the mobile app; (vi) the customer receives the goods and evaluates the crowdsourcing delivery person; (vii) the crowdsourcing delivery person is paid by the platform. In this case, it is possible to reconstruct logistical operation scenarios by matching growth in consumer demand with underused individual supplies via mobile applications and online platforms [22].

Since the emergence of crowdsourcing delivery, it has been the subject of various studies. At an individual level, 
Chandra et al. [3] pointed out that the resources of the crowd, including people, objects, and entities, provided more possibilities to solve delivery problems arising from the surge of individual packages and delivery vehicles. In this context, cyclists and pedestrians become temporary deliverers due to their own delivery needs [6], and most of them can switch between the roles of the deliverer and recipient. By transporting parcels on the final leg of the delivery process, their utility is maximized [4]. However, the most direct factor that motivates people to register on a crowdsourcing platform is the potential economic advantage [23]. They are paid per order, and as such are rewarded for each order they have completed.

As an intermediary, the crowdsourcing delivery platform uses technological capabilities and information sharing to enable crowds and customers to interact with each other [12]. Bauer et al. [23] described information and communications technology (ICT) as an enabler and connector in the entire value chain, including initiating crowdsourcing requests, communicating, processing tasks, reporting solutions and problems, and paying people. With the enormous growth of ICT, paying people working in a crowdsourcing environment has become more convenient than ever [24], which has attracted many people to join the crowdsourcing delivery sector. According to the report released by the Meituan Research Institute, more than 2.7 million people registered on the Meituan Crowdsourcing Delivery Platform in 2018 [25]. Mladenow et al. [12] pointed out that crowdsourcing delivery was essentially location-based crowdsourcing (LBCS), and people could receive a wide range of information and services for a better crowdsourcing experience with GPS or WLAN positioning techniques. Consequently, people who have registered on crowdsourcing platforms in China such as Meituan Crowdsourcing Delivery, Dada Express, and JD Crowdsourcing Delivery have free access to smartphones and location-based services to receive (delivery) orders.

Crowdsourcing delivery plays an increasingly important part in the last mile delivery. More specifically on the performance of crowdsourcing delivery, Castillo et al. [13] have examined the impact of uncertainty related to crowdsourcing delivery on the effectiveness of the logistical process and suggested that the variables of time windows and daily demand variability would be detrimental to the logistical effectiveness of a crowdsourcing fleet compared to that of a dedicated one. In contrast to Castillo et al. [13], Devari et al. [26] demonstrated the broad application prospects of the social network in the last mile delivery in terms of reducing costs and emissions, while maintaining delivery reliability. Also, Behrend and Meisel [27] integrated item-sharing with crowd shipping on the same platform and included three transfer modes, and the optimization solution showed that a platform's profits could increase dramatically through crowd shipping in all three modes.

Concerning the exploration of an intelligent approach in crowdsourcing delivery, Wang et al. [5] proposed an optimization model that utilized a pool of urban crowds to complete the delivery tasks, and the corresponding solution could well optimize real-time delivery in the context of large- scale mobile crowdsourcing. Kafle et al. [4] designed a cyclist- and pedestrian-based system to relay parcels from a truck carrier using a tabu search-based algorithm, and the final result showed a reduction in both delivery miles and involved costs. Giret et al. [6] used multiagent system techniques and complex network-based algorithms to design an intelligent crowd-based approach to sustainable last mile delivery, and the test showed that the approach significantly reduced $\mathrm{CO}_{2}$ emissions and the use of trucks. Similarly, Chandra et al. [3] developed a simulation framework by leveraging crowdsourced big data to improve truck mobility and realize a "smart freight" solution by avoiding downstream congestion in the delivery route.

Existing studies indicate the broad application prospects of crowdsourcing delivery. Much attention has been paid to the topics of individual utility, ICT, application effectiveness, and intelligent approach. In most cases, the management of the crowds or individuals, in particular about competence analysis, is not included, even though it is vital for crowdsourcing delivery personnel to be competent in their jobs, simply because the quality of crowdsourcing delivery service depends on it [5]. As a result, we attempt to connect the individual competence with the crowdsourcing delivery environment. To this end, the competence theory is introduced.

2.2. Competence Analysis. The concept of the competence analysis was developed by McClelland [28], who argued that traditional academic aptitude and knowledge tests did not fully evaluate job performance or real-life outcomes and were often biased against minorities, suggesting using research methods that could identify unbiased "competency" variables and elicit job performance instead. The concept of competence is a topic of ongoing discussion. Messick [29] defined competence as what a person knew and could do while embracing the structure of knowledge and abilities under ideal circumstances, while Gonczi et al. [30] viewed competence as a set of attributes related to professional knowledge, skills, and attitudes, and Beaumont [31] stated that competence was the ability to apply knowledge, understanding, and skills in performing the tasks and roles required by a set of performance standards. Similarly, Kurz and Bartram [32] argued that competence referred to an individual's specific attainment under the constraint of multiple performance criteria, while also pointing out that although the two words "competence" and "competency" may be very similar, they conveyed different meanings: the former was much related to the performance and attainments, while the latter exhibited the antecedents underpinning outstanding performance. In the context of $\mathrm{O} 2 \mathrm{O}$, Cheng et al. [11] defined competence as an offline entity's ability to provide services and complete the desired task at the quality required. Based on these various definitions, it may be clear that the concept of competence is multidimensional and work environment-related [14].

As with the various attempts to define the concept of competence, its connotation and extension are constantly expanding and evolving. During this course, we have 
searched for articles in the databases of Web of Science, Elsevier, Springer, and Wiley with the keywords "competence," "individual competence," and "competence framework" and made a summary of the existing competence frameworks (see Table 1).

Although the first three dimensions in Table 1 (cognitive competence, functional/behavioral competence, and social/ ethical competence) are defined as different terms, they have the same meaning as Knowledge, Skills, and Abilities (KSA) [36]. As such, KSA provides the basic elements of competence. Other dimensions of competence, such as metacompetence, qualification, motor skills, social skills, and information, can still be attributed to the KSA classification indicated above according to their components, while discretion, attitudes, and standards can be assigned to the dimension of traits.

Based on the frameworks for individual competence, there have been useful studies on competence assessment. Gonczi [40] pointed out that competence cannot be observed directly, but it can only be inferred from people's performance. Kurz and Bartram [32] also believed that measuring competence in the workplace involves assessing people's performance using predefined occupational or work-related standards. Therefore, under the performancebased evaluation, the evaluator will assess whether an individual meets the criteria specified in the competence standard based on that individual's performance [14]. Wass et al. [41] pointed out that multiple-choice questions, short essays, and oral examinations can be applied to assess clinical competence, which was following the pyramid framework for clinical competence proposed by Miller [42]. McRobbi et al. [43] designed a competence grid for junior pharmacists by inviting a steering group of clinical pharmacists, academics, and clinical pharmacy managers to develop three competency clusters, using a four-point scale to assess the performance of junior pharmacists. They also pointed out that this grid could be integrated into competence measures in other areas of practice and disciplines. Concerning educational competence, Hartig et al. [44] developed a new service structure for technology-based assessment, which as such provided strong support for research projects by using IT tools to test and assess learning competence and educational quality, while Shavelson [38] proposed an assessment triangle (construct, observation, and inference), in which the generalizability theory and statistical theory were adopted for modeling, and applications were applied in education, business, and military to assess people's competence, and finally the dependability of competence scores was verified. Safadi et al. [45] conducted a cross-sectional survey to assess the level of competence of nursing graduates in five competence dimensions (management, professionalism, problem-solving, nursing process, and the knowledge of basic skills) and concluded that nurse recruitment policies should consider individual competence rather than innate characteristics. As a set of valuable assessment instruments, some well-known competence assessment frameworks, such as European Qualifications Framework, European e-Competence Framework, Competence Assessment Information System
MyCompetence, Occupational Information Network $(\mathrm{O} * \mathrm{NET})$, and European Skills/Competences, Qualifications, and Occupations (ESCO), were developed and applied to a broad range of users to provide general and comprehensive competence reference and outcome assessment [46].

The abovementioned studies reveal that there has been considerable and varied research, often with good results, especially in terms of establishing some mature competence assessment frameworks. However, the existing theoretical research of individual competence focuses predominantly on clinical, medical, psychological, educational, and other areas. We also find that research in the area of logistics is relatively scarce, which is why we apply competence frameworks to that domain and conduct competence analysis of crowdsourcing delivery personnel. Moreover, there is no multicriteria approach provided for using these frameworks in real-world situations, which is why, in the next section, we present an MCCA methodology that helps both researchers and managers to use these frameworks in a practical setting.

\section{Methodology}

3.1. MCCA Methodology. The previous section shows that the existing frameworks consist of several main dimensions and subdimensions, while each dimension describes the specific job standards or performance criteria for the personnel involved. This means that the frameworks include several criteria that are used to evaluate a certain number of personnel (alternatives), which implies that we could formulate an analysis as a multicriteria decision analysis (MCDA). If we take the dimensions as criteria (with some subcriteria) and the personnel as alternatives, this type of competence analysis can be viewed as a multicriteria competence analysis (MCCA) and therefore provides a new approach to evaluating the competence of personnel. MCDA methods can be employed to implement the MCCA approach. In this case, in the MCCA approach, the main components are the criteria and their weights and the personnel and their competence scores. For MCCA, one could select a framework from the previous section, in which the occupations, the opinion of the managers, and the other factors could play a role.

As a generic framework for evaluating the competence of personnel, the steps of the MCCA approach are described as follows.

\subsubsection{Step 1. Determining the Objective of the Competence} Analysis and Defining the Scope of the Problem. The MCCA aims to identify the competence level of personnel. As such, the first step is to define the goal of the analysis. Generally, there are four different goals: (i) evaluation, where the aim simply is to identify the level of competence of each individual; (ii) selection, where the goal is to select personnel based on their competence level; (iii) ranking, where the aim is to rank several personnel members in a given work environment; and (iv) classification or sorting, where the aim is to differentiate between different classes of personnel. It is, of 
TABLE 1: Frameworks for individual competence.

Framework Dimensions and their meanings

Knowledge: a usable body of facts and concepts, retention of information, whether technical, or a method of communication

Skill: the ability to state a goal, list the action sequence, and think logically and systematically; problem-solving ability,

KSMTSS [33] accurate self-assessment, interpersonal ability to manage or orchestrate the work of a team

Motive: a desire to achieve goals as a reflection of improving one's performance

Trait: physical control, a disposition to take an initiative, risk orientation

Self-image: a person's self-assessment of the values and personal characteristics

Social role: a person's perception of a set of social norms, fit in the expectation of social groups

Cognitive competence: formal professional knowledge, tacit-practical knowledge, procedural knowledge, and contextual knowledge as well as knowledge application

Functional competence: occupation-specific function, process management, mental and physical skills

CFBE [34]

Behavioral competence: confidence, persistence, independent thinking, emotional and stress control, listening skills, task-centered awareness, interpersonal skills

Ethical competence: abide by the laws, the rule of morality, be sensitive to the needs of others and value, adopt appropriate attitudes, abide by the professional code of conduct, self-regulation, environmental sensitivity, customercenteredness, moral judgment, acknowledge boundaries of own competence, keep up to date

Knowledge: use data, facts, and information about things and processes and understand the rationale and why in professional practice

KSEQ [32]

Skills: identify problems, coordinate conflicting information, make a judgment in time and apply techniques and procedures to the job

Experience: the history of accumulated job experience

Qualifications: requirements for individuals to engage in certain occupations such as professional license and organization-specific training

Cognitive competence: technical/theoretical knowledge, procedural knowledge, informal tacit/practical knowledge, contextual/background knowledge

Functional competence: "know how" things that an individual who works in a particular career field should be able to do and demonstrate, such as directing subordinates, goal and action management, human resource management, focus on others

CFPSM [35, 36] Personal competence: Decisive action, ethical behavior, communication, focusing on results, influence others, selfmanagement, information searching

Social competence: ability and willingness to cooperate, interact responsibly with others, act in a team and relationshiporiented manner

Meta-competence: ability to facilitate the acquisition of the other substantive competences or skills

Knowledge: a body of various professional knowledge such as law, business, manufacturing, communications, arts, health services engineering, and mathematics

Skills: content skills, process skills, resource management, social skills, technical skills, systems skills, and complex problem-solving skills

KSAOs [37] Abilities: physical abilities like flexibility, balance, and coordination; cognitive abilities like verbal, memory, and

perceptual; psychomotor abilities like control movement, reaction time, and fine manipulative; and sensory abilities like auditory and speech

Other characteristics: achievement orientation, interpersonal orientation, conscientiousness, adjustment, social influence, and practical intelligence

Ability: task performance, the potential for performance under certain situational supports and constraints Performance: know-how ability to perform physically or mentally, or both

Standardization: required tasks or responses to elicit performance are identical, identical working conditions, same administration for all test participants

APSRSI [38]

Real-life: performance has to be observed in real-life situations

Standards: some level or standard of performance, such as "adequate," "sufficient," "proper," "suitable," or "qualified" Improvement: competence is malleable, deliberate practice, education or some other environmental intervention can be used as tools for improvement

Knowledge: disciplinary knowledge, specific professional knowledge

KSA [14] Skills: working with artifacts, multitasking, processing information, instant decision-making Attitudes: accuracy, coping with pressure, integrity, stress tolerance, feeling for specific jobs

Knowledge: disciplinary knowledge, knowledge base and cognitive competence Skills: working with artifacts, functional competence, and perceptual motor skills

Attitudes: affective factors and meta-competence

KSASPDICL

[39]
Sociality: social skills, social interaction, and social role

Personal traits: individual merit

Discretion: mode of behavior, intuition, and revelation

Information: information processing and methodology

Context: specific situation and task, background, and culture

Learning: mode of learning, professional learning 
course, necessary to specify the work environment and occupational attributes of the personnel involved before conducting the following analysis because the MCCA approach is closely associated with the work environment. In this step, for instance, the work environment could be a logistics company, and personnel's occupational attributes could be defined by logistics managers. The work environment is a key factor in defining relevant criteria (Step 2).

\subsubsection{Step 2. Determining the Evaluation Criteria for} Competence Analysis of the Personnel through Competence Analysis Frameworks and Experts' Opinions. In this step, different occupational attributes determine the variation in the criteria for evaluating the competence of personnel. For example, evaluation criterion $\mathrm{C}$ for logisticians $\mathrm{P}$ could involve several aspects: technology skills, transportation knowledge, customer and personal service, coordination skills, information ordering, deductive reasoning, communicating abilities, professional ethics, and work styles. The criteria present multidimensional attributes, which can increase the difficulty of the determination process. Thus, based on the theoretical competence analysis frameworks, it is also important to include the experts' opinions of the company in question to determine the evaluation criteria [47]. Generally, an MCCA problem can be formulated as a matrix as follows:

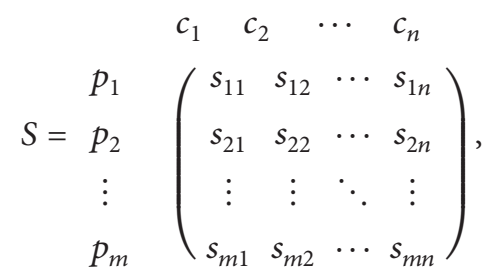

where $C=\left\{c_{1}, c_{2}, \ldots, c_{n}\right\}$ denotes a set of evaluation criteria for competence analysis, $P=\left\{p_{1}, p_{2}, \ldots, p_{m}\right\}$ indicates a group of personnel, and $s_{i j}$ represents the corresponding competence score of each individual $i$ for criterion $j$.

3.1.3. Step 3. Collecting Competence Scores of Each Individual for All Criteria from Various Data Sources. Competence scores $s_{i j}$ need to be collected from the department where personnel are employed in various ways, like internal statistics, questionnaires, and interviews. Due to the variety of data sources, for all criteria $C$, the competence scores $s_{i j}$ may use scales, like minutes, miles, money, and rates. To ensure the criteria can be compared to each other and further perform the MCCA [48], the competence scores need to be normalized, for instance, using the following normalization method:

$$
s_{k j}^{\text {norm }}=\left\{\begin{array}{l}
\frac{s_{k j}}{\max \left\{s_{i j}\right\}}, \text { for a positive criterion, } \\
1-\frac{s_{k j}}{\max \left\{s_{i j}\right\}}, \text { for a negative criterion. }
\end{array}\right.
$$

3.1.4. Step 4. Finding the Optimal Weights of All Criteria That Have Been Identified for the Competence Analysis. Given all the predetermined criteria for competence analysis of personnel, finding the weight $w^{*}=\left\{w_{1}, w_{2}, \ldots, w_{j}\right\}$ of all criteria $C$ is an essential part, for which, in this step, a multicriteria weighting method can be applied, including SMART (simple multiattribute rating technique) [49], AHP (analytic hierarchy process) [50], ANP (analytic network process) [51], and BWM (best-worst method) [52].

This is an important part of MCCA, as the decision makers could differentiate among the evaluation criteria. While in particular cases, Knowledge may be a very important dimension of personnel competence, in other situations, Skills may be a more relevant dimension. This step incorporates the opinions of managers regarding the importance of the criteria into MCCA.

3.1.5. Step 5. Finding an Overall Level of the Personnel Competence with Aggregating the Scores. Determining the overall competence level of the personnel is the final part of MCCA. After determining the weights of the criteria, the aggregated score for each individual $i$ can be calculated. In this step, the aggregation process can also assume different forms, for instance, as an additive value function [53]. As shown in (3), the aggregated score $v_{i}$ can be based on the weight $w_{j}$ and $s_{i j}^{\text {norm: }}$

$$
v_{i}=\sum_{j=1}^{n} w_{j} s_{i j}^{\text {norm }}, \quad \forall i=1,2, \ldots, m,
$$

where $w_{j} \geq 0$ and $\sum_{j=1}^{n} w_{j}=1$.

Then, for any occupation, the competence level of individual $i$ is better than of $i^{\prime}$ if and only if $v_{i}$ is greater than $v_{i^{\prime}}$ or

$$
i>i^{\prime} \Longleftrightarrow v_{i}>v_{i^{\prime}} \text {. }
$$

The MCCA approach developed here indicates a new direction for assessing the competence level of personnel, which integrates the comprehensive impact of multiple criteria with an MCDA method. As such, the resulting competence level is a more comprehensive measure of how competent people are for their particular jobs. In addition to the final scores of the personnel involved, the MCCA approach also shows the path to identify the key elements of the criteria that have been identified on personnel competence level. With the help of the weights that have been assigned to the criteria, the core requirements for the competence of personnel can be determined. As a generic framework, the MCCA approach can be applied to a variety of occupations.

3.2. Bayesian Best-Worst Method. Given the MCCA methodology, we need to select an appropriate method to implement it. For our case study, we use BWM $[52,54]$ because of its several attractive features: (i) BWM requires the DM identifying the best and worst criteria (or alternatives) at the very first before conducting a pairwise comparison, and it enables the DM to have a more explicit vision of the range of 
the evaluation. Consequently, this allows for more reliable comparisons, as well as better consistency of the comparisons [52]. (ii) It is possible to mitigate the anchoring bias that arises during the DM's pairwise comparisons in a single optimization model by using two opposing references, the best and the worst [55]. BWM is highly consistent with this procedure, and this kind of consider-the-opposite-strategy have been proven effective [56]. (iii) BWM better balances the data and time efficiency in the structured pairwise comparison-based method [55]. On the one hand, BWM offers the possibility to check the consistency of the pairwise comparisons provided. Compared to methods using a single vector such as the Swing and SMART family, BWM bridges the gap where pairwise comparison consistency check is not available, despite the high data (and time) efficiency of such single vector input-only methods. On the other hand, BWM enhances data efficiency compared to full-matrix methods such as AHP. While pairwise comparisons under the fullmatrix method offer the possibility of checking consistency, it poses too many questions to the DM, which may lead to confusion and inconsistency.

The method has been applied to many real-world problems, including logistics [57], IoT [58], water security sustainability evaluation [59], energy technology selection [60], manufacturing [61], supplier selection [62], airport evaluation [63], and many more, see [64].

There are several extended versions of BWM $[52,54,65,66]$, and in this paper, we use the Bayesian BWM. Considering the decision makers (DMs) are a group, it offers an ideal approach from a probabilistic angle to determine the overall weights. The Bayesian BWM is based on the original BWM, so the input, i.e., the pairwise comparisons, is the same. However, as for the output, there is a difference between the two methods. In the original BWM, the final output is a concrete value of the weight, while the Bayesian BWM provides a probability distribution. Specifically, the Bayesian BWM includes the following steps:

Step 1. Determining a set of decision criteria $C=\left\{c_{1}, c_{2}, \ldots, c_{n}\right\}$.

Step 2. Determining the best $\left(c_{B}\right)$ and the worst $\left(c_{W}\right)$ criteria from $C$. In this step, no pairwise comparison of the DMs is required, and they only identify the best or most important criterion and the worst or least important criterion.

Step 3. Conducting the pairwise comparison between the best criterion and the other criteria using a number between 1 and 9. The higher the number, the stronger the relative importance between the criteria. The resulting Best-to-Others vector is $A_{B}=\left(a_{B 1}, a_{B 2}, \ldots, a_{B n}\right)$, where $a_{B j}$ denotes the preference of the best criterion $c_{B}$ over other criteria $c_{j} \in C$.

Step 4. Conducting the pairwise comparison between the other criteria and the worst criterion using a number between 1 and 9. The resulting Others-toWorst vector is $A_{W}=\left(a_{1 W}, a_{2 W}, \ldots, a_{n W}\right)^{\mathrm{T}}$, where $a_{j W}$ indicates the preference of the criterion $c_{j} \in C$ over the worst criterion $c_{W}$.

Step 5. Estimating the probability distribution of each individual optimal weight $w^{1: K}$ and the overall optimal weight $w^{\text {agg }}$ given $A_{B}^{1: K}$ and $A_{W}^{1: K}$, where $k$ represents the DM and $k=1, \ldots, K$.

To this end, the joint probability distribution is used:

$$
P\left(w^{\mathrm{agg}}, w^{1: K} \mid A_{B}^{1: K}, A_{W}^{1: K}\right) .
$$

Based on (5), the probability of each variable then can be computed with the sum rule:

$$
P(x)=\sum_{y} P(x, y)
$$

where $x$ and $y$ denote two arbitrary random variables.

To build a Bayesian model, a probabilistic hierarchical model is plotted, as shown in Figure 1, to clarify the relationship between the different variables.

It is clear that the variable $w^{k}$ depends on both $A_{B}^{k}$ and $A_{W}^{k}$, while $w^{\text {agg }}$, in turn, depends on $w^{k}$, while either $A_{B}^{k}$ or $A_{W}^{k}$ is independent of $w^{\mathrm{agg}}$ according to the direction of the arrow. This independence feature can be described as follows:

$$
P\left(A_{W}^{K} \| w^{\mathrm{agg}}, w^{K}\right)=P\left(A_{W}^{K} \| w^{K}\right) .
$$

Combining Bayes theorem with (5) provides the following equation:

$$
P\left(w^{a g g}, w^{1: K} \| A_{B}^{1: K}, A_{W}^{1: K}\right) \propto P\left(A_{B}^{1: K}, A_{W}^{1: K} \| w^{a g g}, w^{1: K}\right) P\left(w^{\mathrm{agg}}, w^{1: K}\right)=P\left(w^{\mathrm{agg}}\right) \prod_{1}^{K} P\left(A_{W}^{K} \| w^{K}\right) P\left(A_{B}^{K} \| w^{K}\right) P\left(w^{K} \| w^{\mathrm{agg}}\right) .
$$

To further compute the posterior distribution, the variables in (8) have to be specified. As the input of BWM, $A_{B}^{k}$ and $A_{W}^{k}$ can be modeled by multinomial distribution due to the property of the integer, resulting in

$$
A_{W}^{k} \mid w^{k} \sim \operatorname{multinomial}\left(w^{k}\right), \quad \forall k=1, \ldots, K .
$$

Although it also applies to the vector $A_{B}^{k}$, the difference between $A_{B}^{k}$ and $A_{W}^{k}$ yields the reverse weight, as follows:

$$
A_{B}^{k} \mid w^{k} \sim \text { multinomial }\left(\frac{1}{w^{k}}\right), \quad \forall k=1, \ldots, K .
$$

We then need to determine the weight $w$ in the multinomial distribution, and the Dirichlet distribution will act 


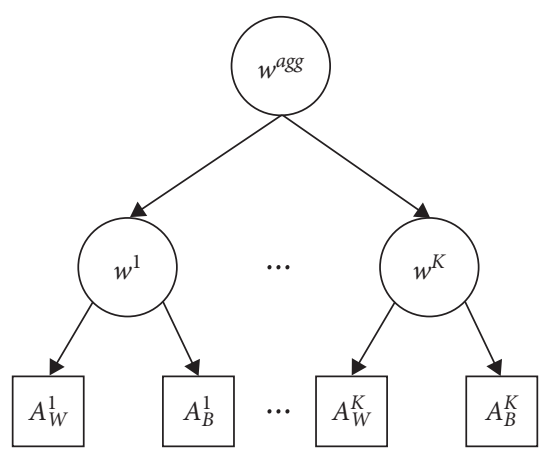

FIgURe 1: Probabilistic hierarchical model of the Bayesian BWM.

as the prior distribution to model $w$ because of its nonnegativity and sum-to-one properties:

$$
\operatorname{Dir}(w \| \alpha) \sim \frac{1}{B(\alpha)} \prod_{j=1}^{n} w_{j}^{\alpha_{j}-1}, \quad \alpha \in \mathbb{R}^{n} .
$$

Equation (11) depicts the probability density function of the continuous random variable $w$ when it obeys the Dirichlet distribution. Therein, $B(\alpha)$ is a multivariate beta function, and $B(\alpha)=\prod_{j=1}^{n} \Gamma\left(\alpha_{j}\right) / \Gamma\left(\alpha_{0}\right) . \Gamma(\alpha)$ is the gamma distribution; $\alpha_{j}$ is the dimensionless distribution parameter, and $\alpha_{j}>0, j=1,2, \ldots, n ; \alpha_{0}$ is the sum of the distribution parameters, i.e., $\alpha_{0}=\sum_{j=1}^{n} \alpha_{j}$ [67].

Then, for every individual weight $w^{k}$ in (9) or (10), when $w^{\text {agg }}$ is given, it is expected to be in the proximity of $w^{\text {agg }}$. For this purpose, the Dirichlet distribution has to be reparametrized regarding its mean and concentration parameter:

$$
w^{k} \| w^{\mathrm{agg}} \sim \operatorname{Dir}\left(\gamma \times w^{\mathrm{agg}}\right), \quad \forall k=1, \ldots, K,
$$

where $w^{\text {agg }}$ indicates the mean of the distribution and the nonnegative parameter $\gamma$ denotes the closeness between $w^{k}$ and $w^{\text {agg }}$, i.e., concentration parameter. Also, $\gamma$ needs to be modeled and the gamma distribution can be adopted:

$$
\gamma \sim \Gamma(a, b)
$$

where $a$ and $b$ are the shape parameters of the gamma distribution, and the values are both set to 0.1 [68] because with such settings, the gamma distribution is similar to the uniform distribution, thus it has minimum effect on the posterior distribution [65]. Moreover, Bayesian BWM uses estimation to get the weights of the probability distribution. As such, when we do not know the valid values of certain parameters, we use uniform-like distributions and let the data skew the values. This means that when only partial knowledge about the unknown distribution is available, the probability distribution that conforms to this knowledge but has the maximum entropy value should be selected, which is also the idea underlying the maximum entropy principle [69].

Finally, we employ an uninformative Dirichlet distribution to provide a prior distribution of $w^{\text {agg }}$ with the setting of the parameter $\alpha$ to 1 [65]. Then, the aggregated weights $w^{\text {agg }}$ can be can be described as

$$
w^{\text {agg }} \sim \operatorname{Dir}(1)
$$

The Bayesian model defined by the above equations does not output a closed-form solution. Therefore, the Markov chain Monte Carlo (MCMC) [70] is required to compute the posterior distribution in equation (8) where the "just another Gibbs sampler" (JAGS) [71] is used to generate the random sample.

\section{Case Study}

To illustrate the MCCA approach, we conducted a real-world case study where the goal is to analyze the competence of the crowdsourcing delivery personnel in Chongqing, China. To this end, a survey and the Bayesian BWM are adopted to assist in the data collection and weight acquisition, respectively. The overall steps of the case study are outlined in Figure 2.

4.1. Criteria Determination. Competence measurement involves the evaluation of workplace performance against a number of predetermined occupational or job-related multiple criteria [32]. Of the multiple criteria that are listed in the competence analysis framework in Section 2, this paper does not include the dimension of Qualification, mainly because certain formal knowledge thresholds may be required, but not all of them require initial qualifications [72]. It is also in accordance with the actual situation where some Chinese crowdsourcing delivery platforms do not set a high entry barrier or require strict qualifications for people who want to register as crowdsourcing delivery personnel, as long as they have a valid ID and health certificate (https://peisong.meituan.com/).

Combined with the competence analysis framework, the main criteria involved are Knowledge, Skills, Abilities, and Traits (KSAT). The subcriteria are based on the interpretation of KSAT's components and the views of different scholars in literature because they are rarely included in any studies into competence in the area of crowdsourcing delivery. In addition, we consult with experts and include their opinions to identify the final subcriteria. The resulting MCCA framework for crowdsourcing delivery personnel is shown in Table 2.

4.2. Data Collection. In line with the MCCA approach, we need to obtain the competence scores. In this instance, we collected data regarding the crowdsourcing delivery personnel from the Meituan takeaway platform in Chongqing, China, combining the platform's statistical data with telephone interviews. First, the basic statistic data, like average delivery time, total delivery mileage, and customer ratings, were collected through the takeaway platform's mobile app from different users. However, some data, like total order quantity, registration time, relevant work experience, etc., were still not directly accessible, which meant that, in the second step, using the work telephone number displayed in the mobile phone app, we conducted a 30-minute telephone interview to collect the data from crowdsourcing delivery personnel of the same platform. Based on the principle of data availability and usefulness, we finally were able to collect the data of 81 different people. 


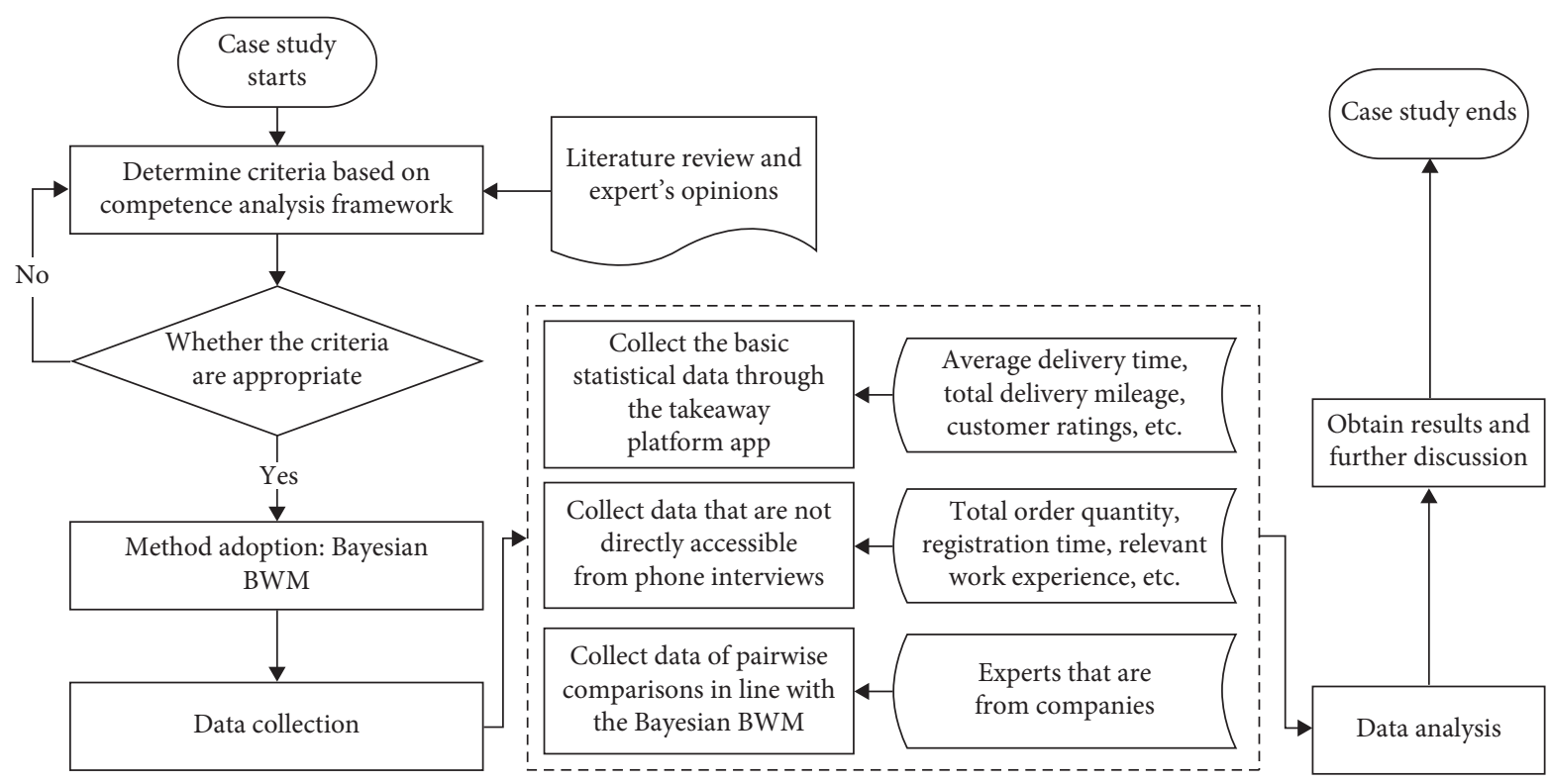

Figure 2: Case study flowchart.

As for the data processing, the data of subcriteria "Knowledge of crowdsourcing delivery," "Previous job experience," and "Customer service awareness" mainly reflect the richness of knowledge and experience, and a 5-point Likert scale (from very low 1 to very high (5)) [75] was used to process the linguistics information acquired from the selfreports by the crowdsourcing delivery personnel, after which the method in (2) is used for data normalization.

Following the steps in the Bayesian BWM, questionnaires were sent to 15 site managers of the Meituan takeaway platform. Based on their input, the daily duties of the site manager can be summarized as follows: recruitment and management of riders; statistics and analysis of site data; promotion of site scale; organization of rider activities; routine training of riders; management training and relationship management of cooperative merchants; supervising service quality; and properly handling customer complaints and various contradictions from delivery service. Of the managers involved, two managers are from Kaizhou District, Chongqing, two managers are from Nan'an District, Chongqing, two managers are from Jiangbei District, Chongqing, two managers are from Wanzhou District, Chongqing, and three managers from Shapingba District, Chongqing. In addition to Chongqing, the rest of the site managers are from Zhengzhou, Henan Province, two are from Zhongyuan District, and the other two managers are from Jinshui District. To ensure that all the site managers have adequate information to conduct the comparisons, some documents describing the Bayesian BWM and the competence criteria of the crowdsourcing delivery personnel are also provided.

\section{Results and Discussion}

In this section, we first present the weights of the criteria, after which we discuss the credal ranking, which elaborates the confidence of the rankings. Finally, we present a ranking of the personnel based on the weights and competence scores.

5.1. Criteria Weights. The output of the aggregated weights is a Dirichlet distribution in the Bayesian BWM. Prior to obtaining the final weights and calculating the competence scores, the average of the Dirichlet distribution of aggregated weights needs to be computed [65]. The average weights of the main criteria and subcriteria, as well as the overall weights, are listed in Table 3.

Table 3 reveals that "Total mileage" has the lowest priority of all the 14 subcriteria, while "Punctuality" and "Customer service awareness" are the most important. For the crowdsourcing delivery personnel, the delivery radius is about $4 \mathrm{~km}$, while the delivery radius of dedicated delivery personnel is 2.5 to 3 kilometers. The delivery radius directly affects their delivery mileage. Even with the same number of orders per day, there can be a significant difference in delivery miles between the two groups. Therefore, the competence or effective performance for the crowdsourcing delivery personnel does not necessarily depend on the length of the delivery miles, but more on the time within which the order is delivered [7]. Crowdsourcing delivery is real-time delivery, and unlike normal express delivery, goods have to be delivered to customers within a very short period, so timeliness and customer service awareness are particularly important competence criteria. In addition to "Punctuality" and "Customer service awareness," the subcriteria "Responsible" and "Goods intact" rank very high as well. These four subcriteria make up the basic requirements for the competence of the crowdsourcing delivery personnel, which means that they need to have a certain awareness of customer service and deliver the customer's goods intact and on time in a responsible manner. 
TABLE 2: MCCA framework for the crowdsourcing delivery personnel.

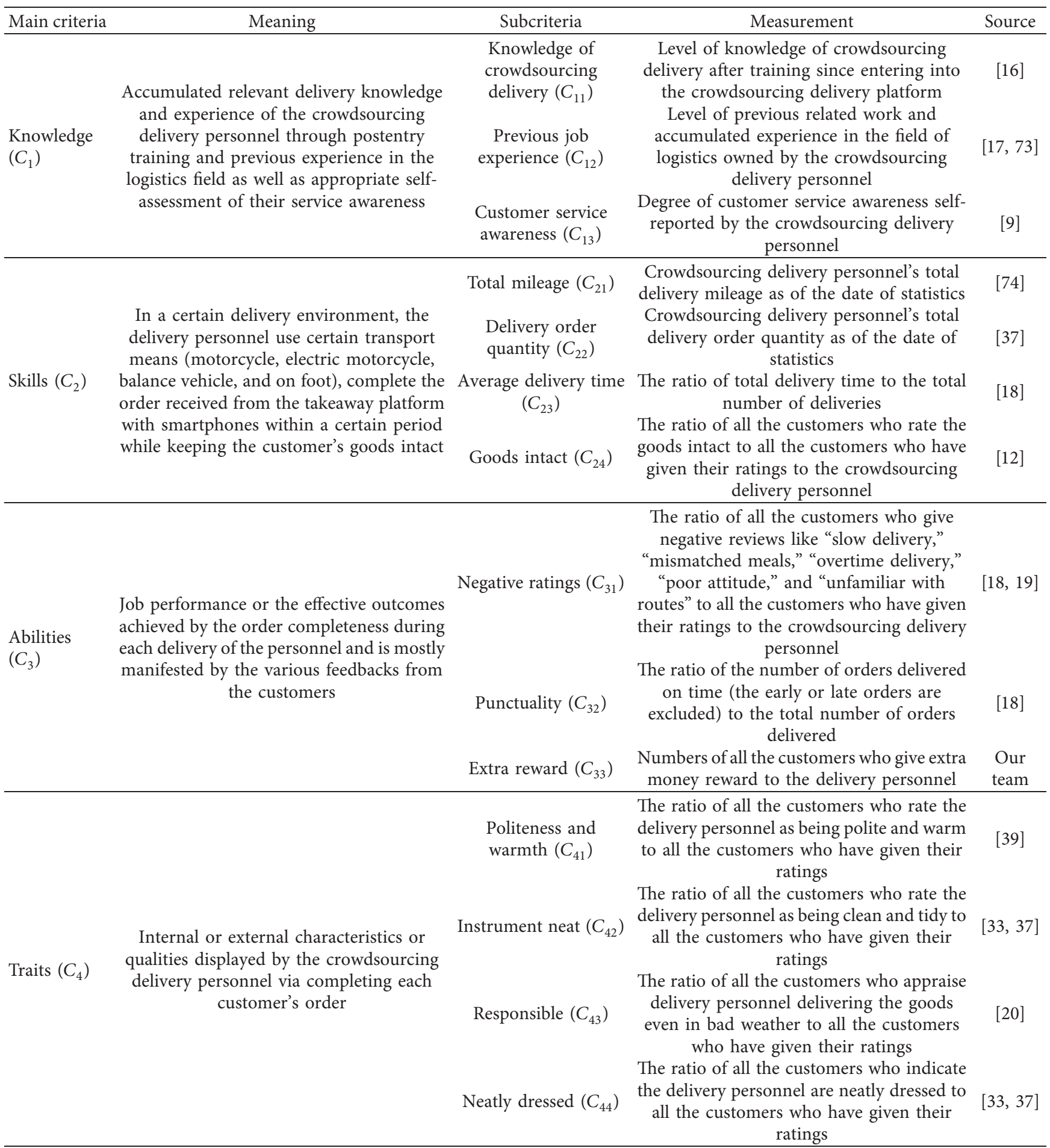

For the measurement of the relationship between a pair of criteria, the Bayesian BWM introduces the concept of credal ranking [65]. Compared to the traditional way, which merely uses two figures to determine the confidence superiority, it devises a Bayesian test to compute the confidence of each credal ranking. By applying this principle to the realworld case, the confidence superiority between different pairs of competence criteria can be computed.
As shown in Figure 3, "Skills" is the most important of all the main criteria. This is mainly because for a specific job or profession, the skill reflects people's ability to perform the tasks and roles according to the expected standards or requirements [12]. They are required to be prequalified to make sure that they have the necessary skills to perform at the required quality [16]. Essentially, crowdsourcing delivery personnel provide a more convenient service to various 
TABle 3: Weights of main criteria and subcriteria.

\begin{tabular}{|c|c|c|c|c|}
\hline Main criteria & Weight & Subcriteria & Local weight & Global weight \\
\hline Knowledge $\left(C_{1}\right)$ & 0.104 & $\begin{array}{c}\text { Knowledge of crowdsourcing delivery }\left(C_{11}\right) \\
\text { Previous job experience }\left(C_{12}\right) \\
\text { Customer service awareness }\left(C_{13}\right)\end{array}$ & $\begin{array}{l}0.197 \\
0.214 \\
0.589 \\
\end{array}$ & $\begin{array}{l}0.049 \\
0.053 \\
0.147 \\
\end{array}$ \\
\hline Skills $\left(C_{2}\right)$ & 0.396 & $\begin{array}{c}\text { Total mileage }\left(C_{21}\right) \\
\text { Delivery order quantity }\left(C_{22}\right) \\
\text { Average delivery time }\left(C_{23}\right) \\
\text { Goods intact }\left(C_{24}\right)\end{array}$ & $\begin{array}{l}0.107 \\
0.244 \\
0.307 \\
0.342\end{array}$ & $\begin{array}{l}0.027 \\
0.061 \\
0.077 \\
0.086\end{array}$ \\
\hline Abilities $\left(C_{3}\right)$ & 0.366 & $\begin{array}{c}\text { Negative ratings }\left(C_{31}\right) \\
\text { Punctuality }\left(C_{32}\right) \\
\text { Extra reward }\left(C_{33}\right)\end{array}$ & $\begin{array}{l}0.289 \\
0.588 \\
0.123\end{array}$ & $\begin{array}{l}0.072 \\
0.147 \\
0.031\end{array}$ \\
\hline Traits $\left(C_{4}\right)$ & 0.133 & $\begin{array}{c}\text { Politeness and warmth }\left(C_{41}\right) \\
\text { Instrument neat }\left(C_{42}\right) \\
\text { Responsible }\left(C_{43}\right) \\
\text { Neatly dressed }\left(C_{44}\right) \\
\end{array}$ & $\begin{array}{l}0.153 \\
0.178 \\
0.466 \\
0.204 \\
\end{array}$ & $\begin{array}{l}0.038 \\
0.044 \\
0.117 \\
0.051\end{array}$ \\
\hline
\end{tabular}

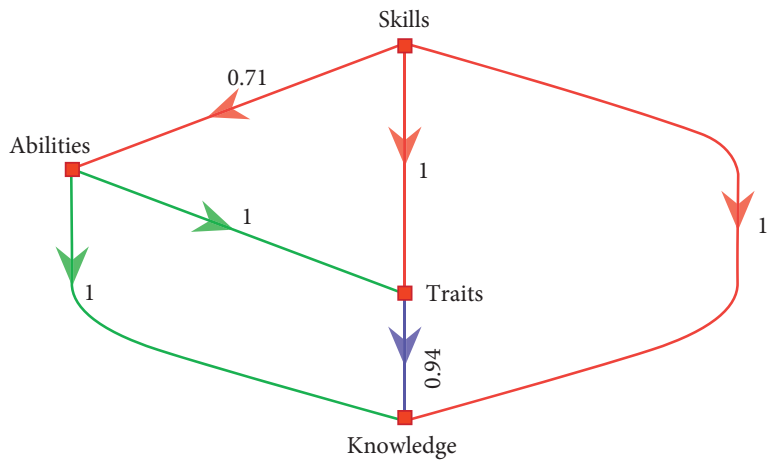

FIGURE 3: Credal ranking for the main criteria.

customers. Therefore, the first and most important criterion to assess whether they are competent as service providers is for them to deliver goods to the right address at the right time [76]. Although "Skills" is considered more important than the other three criteria, a confidence of 0.71 between it and the dimension of "Abilities" implies that some managers believe abilities play a more important role, since the ability is a powerful manifestation of individual performance [38], with skill being a necessary tool to achieve it. The dimension of "Abilities" ranks in second place, which means that, in absolute terms, it is still more important than "Knowledge" and "Traits," with a confidence of 1 . Among the four main criteria, it is not surprising to see that "Knowledge" is considered to be the least important criterion, with even "Traits" ranking higher with a confidence of 0.94. This is in line with the actual situation involving crowdsourcing delivery personnel in China because to attract more people to the crowdsourcing delivery platform the entry barrier is kept relatively low. Besides, the fact that "Traits" is not ranked the lowest implies that personal qualities or characteristics are also considered by experts to be essential elements in ensuring the quality of service demonstrating personnel's competence.

As for the Knowledge dimension, Figure 4 shows that the criterion "Service awareness" is considered the most important one, with a confidence of 1 , which once again confirms the importance of customer service awareness for crowdsourcing delivery personnel, since customer demand is met by the delivery service, and their service awareness to a large extent determines the level of quality of the service being provided [12]. Between previous experience and training knowledge, the former is considered to be more important than the latter, with a confidence of 0.67 , which indicates that the managers believe that people who have previously worked similar jobs are more likely to perform better in their new environment.

The credal ranking for the "Skills" dimension in Figure 5 shows that the criterion of "Goods intact" is considered the most important, with a confidence of 1 against "Total mileage," with a confidence of 0.99 against "Order quantity," and with a confidence of 0.76 against "Average delivery time." The confidence level between "Goods intact" and "Average delivery time" is the lowest, indicating that both time and goods are highly valued by experts in assessing the competence of crowdsourcing delivery personnel. Also, "Average delivery time" is almost as important as "Order quantity" and "Total mileage."

Concerning the "Abilities" dimension, the criterion of "Punctuality" appears to be the most important, as shown in Figure 6, which is also reflected between the "Negative ratings" and the "Extra reward" with a confidence of 1 . This is in line with reality, as the additional reward shows the customer's superior satisfaction with the crowdsourcing delivery service although this will not apply to every single delivery. The frequency with which it occurs will, in turn, affect its importance in assessing the competence of the crowdsourcing delivery personnel.

With respect to the "Traits" dimension, Figure 7 explicitly shows that the criterion of "Responsible" is superior to the other three criteria, with a confidence of 1 , because the delivery time of crowdsourcing delivery personnel is more flexible and the constraints are more relaxed, compared to dedicated delivery personnel [11]. Therefore, the ability to deliver goods to customers in extreme conditions reflects a responsible attitude and professional dedication. Of all the criteria, "Politeness and warmth" is considered to be the least important. 


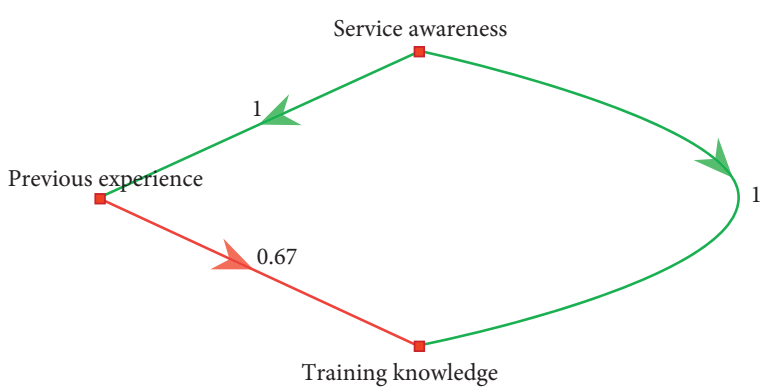

FIgURE 4: Credal ranking for the "Knowledge" dimension.

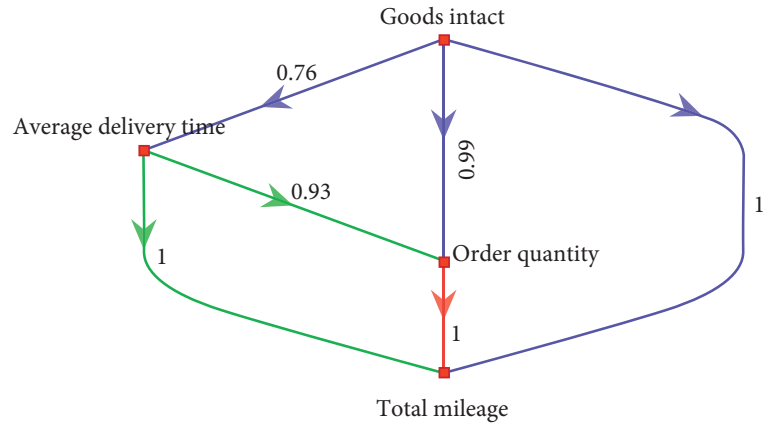

Figure 5: Credal ranking for the "Skills" dimension.

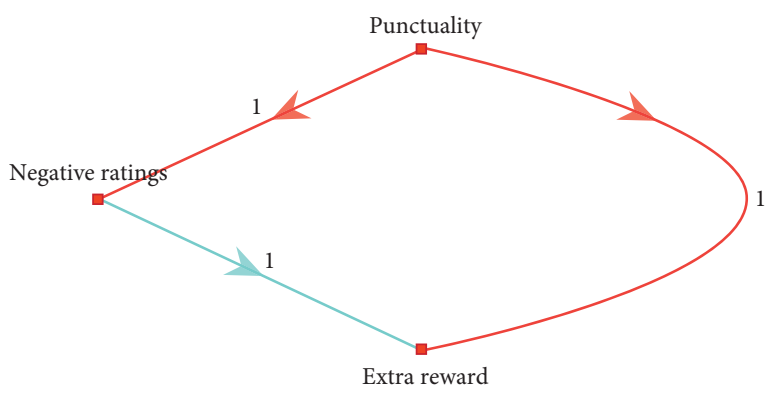

FiguRE 6: Credal ranking for the "Abilities" dimension.

However, the relative importance between the criterion of "Neatly dressed" and "Instrument neat" is not very significant, with a confidence level of 0.78 , which is the lowest of all confidence levels.

5.2. Competence Analysis of Crowdsourcing Delivery Personnel. Combining the weights and data discussed above, the competence scores for crowdsourcing delivery personnel (CDP) are calculated as shown in Table 4. To guarantee the privacy of the crowdsourcing delivery personnel, their names are replaced with numbers.

Based on the competence scores for crowdsourcing delivery personnel in Table 4, some statistic results can be derived, as shown in Table 5 .

Table 5 shows that, among all the crowdsourcing delivery personnel, the highest competence score is assigned to CDP 2, while the lowest score is assigned to CDP 75. CDP 2's competence score is more than twice that of CDP 75. The significant difference between them is

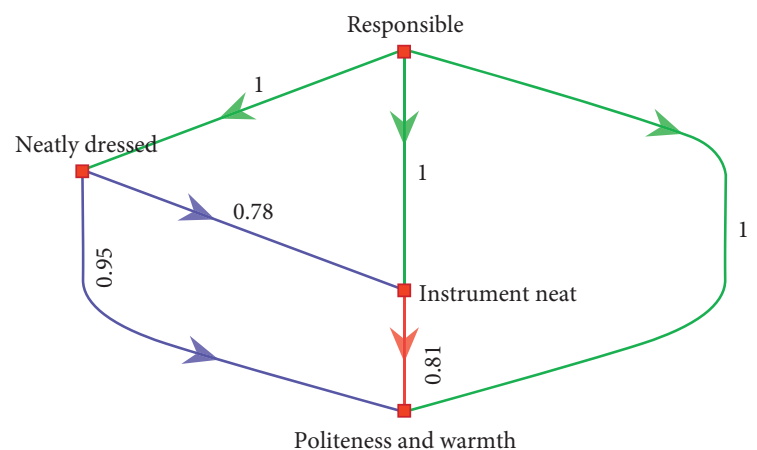

Figure 7: Credal ranking for the "Traits" dimension.

also reflected in the standard deviation, which is relatively high, which also clearly illustrates the fact that the competence of 81 crowdsourcing delivery personnel varies significantly.

Moreover, we attempt to explore the impact of varying length of registration time on the competence of crowdsourcing delivery personnel, dividing them into four groups based on a three-month boundary: Group A (1 to 3 months), Group B (3 to 6 months), Group C (6 to 9 months), and Group D (more than 9 months). The personnel numbers are arranged in descending order accordingly. Similarly, some basic statistical results can be obtained from different groups.

Among the four groups in Table 6, the average competence score of Group A is the highest and Group D is the lowest, with Groups B and C somewhere in between. Together with the overall average score, it can be concluded that of the nearly half of the undercompetent crowdsourcing delivery personnel, $42.5 \%$ are in Group A, 37.5\% in Group B, $15 \%$ in Group C, and 5\% in Group D. In this light, Group A continues to be at the bottom of the competence ranking, while Group D holds the top position, with the value of the standard deviation distributing in the same order. The standard deviation of Group D is the highest and close to that of the overall level in Table 5. By contrast, the standard deviation of Group A is the lowest. There is a considerable difference between the competence scores of the two groups, with the competence of the personnel in Group A being significantly higher and more stable than that of group D. The people in Group D have all worked for the platform for less than 3 months, and most of them joined fairly recently. As such, they do not have the time to gain the proper experience, skills, and training, which explains the difference. On the other hand, there is much less of a difference between the standard deviation of Groups B and C, who represent the people that have worked for the platform for more than 3 months, but less than 9 months, and their overall competence is relatively stable compared with Group D. Of these two groups, the people in Group C perform better than those in Group B, as indicated by the four statistical indicators presented in Table 6.

The group comparison proves the positive impact of registration time on crowdsourcing delivery personnel, which means that, over time, they become more competent, a conclusion that is also supported by Figure 8 . 
TABle 4: Competence scores for crowdsourcing delivery personnel.

\begin{tabular}{|c|c|c|c|c|c|}
\hline Number & Competence scores & Number & Competence scores & Number & Competence scores \\
\hline CDP 1 & 0.666 & CDP 28 & 0.608 & CDP 55 & 0.402 \\
\hline CDP 2 & 0.733 & CDP 29 & 0.586 & CDP 56 & 0.579 \\
\hline CDP 3 & 0.650 & CDP 30 & 0.709 & CDP 57 & 0.558 \\
\hline CDP 4 & 0.625 & CDP 31 & 0.546 & CDP 58 & 0.527 \\
\hline CDP 5 & 0.586 & CDP 32 & 0.565 & CDP 59 & 0.450 \\
\hline CDP 6 & 0.682 & CDP 33 & 0.626 & CDP 60 & 0.668 \\
\hline CDP 7 & 0.659 & CDP 34 & 0.663 & CDP 61 & 0.563 \\
\hline CDP 8 & 0.669 & CDP 35 & 0.703 & CDP 62 & 0.521 \\
\hline CDP 9 & 0.668 & CDP 36 & 0.681 & CDP 63 & 0.487 \\
\hline CDP 10 & 0.650 & CDP 37 & 0.473 & CDP 64 & 0.541 \\
\hline CDP 11 & 0.684 & CDP 38 & 0.577 & CDP 65 & 0.609 \\
\hline CDP 12 & 0.584 & CDP 39 & 0.724 & CDP 66 & 0.504 \\
\hline CDP 13 & 0.692 & CDP 40 & 0.562 & CDP 67 & 0.565 \\
\hline CDP 14 & 0.715 & CDP 41 & 0.599 & CDP 68 & 0.595 \\
\hline CDP 15 & 0.691 & CDP 42 & 0.482 & CDP 69 & 0.569 \\
\hline CDP 16 & 0.550 & CDP 43 & 0.557 & CDP 70 & 0.542 \\
\hline CDP 17 & 0.673 & CDP 44 & 0.544 & CDP 71 & 0.517 \\
\hline CDP 18 & 0.652 & CDP 45 & 0.594 & CDP 72 & 0.530 \\
\hline CDP 19 & 0.564 & CDP 46 & 0.439 & CDP 73 & 0.431 \\
\hline CDP 20 & 0.603 & CDP 47 & 0.670 & CDP 74 & 0.537 \\
\hline CDP 21 & 0.650 & CDP 48 & 0.463 & CDP 75 & 0.314 \\
\hline CDP 22 & 0.600 & CDP 49 & 0.492 & CDP 76 & 0.600 \\
\hline CDP 23 & 0.562 & CDP 50 & 0.534 & CDP 77 & 0.542 \\
\hline CDP 24 & 0.707 & CDP 51 & 0.538 & CDP 78 & 0.520 \\
\hline CDP 25 & 0.601 & CDP 52 & 0.525 & CDP 79 & 0.386 \\
\hline CDP 26 & 0.536 & CDP 53 & 0.587 & CDP 80 & 0.368 \\
\hline CDP 27 & 0.626 & CDP 54 & 0.490 & CDP 81 & 0.366 \\
\hline
\end{tabular}

TABLE 5: Statistical results for overall competence scores.

\begin{tabular}{lllccc}
\hline Personnel & $N$ & Mean & Max & Min & SD \\
\hline Overall & 81 & 0.575 & 0.733 & 0.314 & 0.089
\end{tabular}

TABLE 6: Statistical results for different groups' competence scores.

\begin{tabular}{lccccc}
\hline Group & $N$ & Mean & Max & Min & SD \\
\hline Group A & 20 & 0.502 & 0.609 & 0.314 & 0.082 \\
Group B & 21 & 0.536 & 0.670 & 0.402 & 0.068 \\
Group C & 21 & 0.615 & 0.724 & 0.473 & 0.064 \\
Group D & 19 & 0.652 & 0.733 & 0.550 & 0.049 \\
\hline
\end{tabular}

It is clear from Figure 8 that there is an upward trend when it comes to competence levels. As time progresses, the median of the competence scores of the four groups increases, and the gap between the upper and lower limits narrows. Especially, the fluctuation of the competence scores of Group A is the most obvious, while Group D has minimal fluctuation. This intuitively demonstrates that the more experienced crowdsourcing delivery personnel are not only more competent but that their performance is the most stable as well, with the highest competence score in the other three groups being higher than the lowest score in Group D, which indicates that there are some excellent performers among the crowdsourcing delivery personnel who joined the platform more recently and that they clearly have the competence required. There are some implications for the platform managers. They need to establish a comprehensive

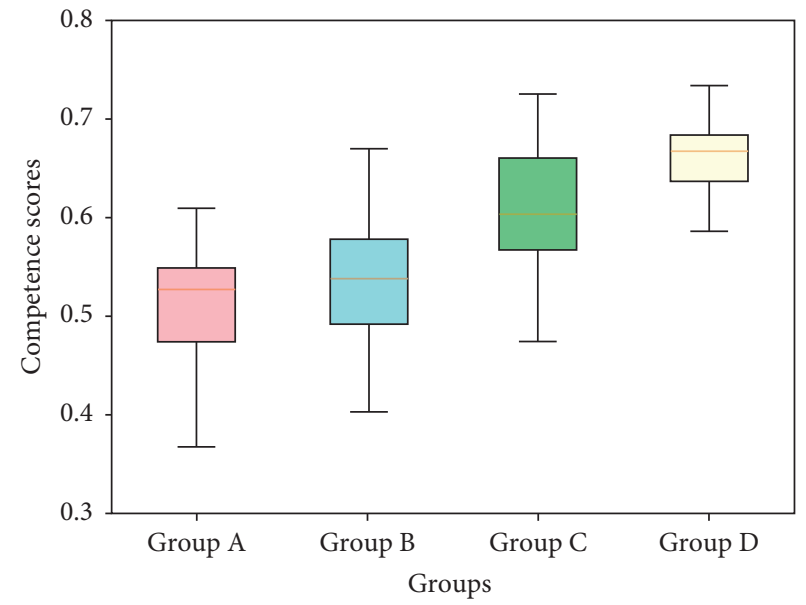

FIGURE 8: Competence scores of different groups.

competence evaluation system for the crowdsourcing delivery personnel and then identify the outstanding ones, especially among those who joined recently. Apart from that, because of the relatively large turnover in crowdsourcing delivery personnel, some monetary and nonmonetary incentive plans need to be formulated to encourage the outperformers to stay longer and provide better service quality.

\section{Conclusions}

In this paper, we conducted a comprehensive competence analysis of crowdsourcing delivery personnel. During this 
process, we developed a multicriteria competence analysis (MCCA) approach as a new way to assess the competence of personnel with the MCDA method embedded to implement the MCCA approach. To illustrate the MCCA approach, we conducted a real-world case study of a Chinese takeaway delivery platform to perform the competence analysis of crowdsourcing delivery personnel and applied the Bayesian best-worst method to identify the weights of the criteria in MCCA. Once the weights were obtained and the competence scores collected, the additive value function was used to generate the overall competence level of the crowdsourcing delivery personnel. The relationship between their competence level and some other variables was also discussed, allowing us to draw the following conclusions.

\subsection{Theoretical Implications}

(1) Combining the crowdsourcing delivery environment with competence evaluation expands the extension of the competence theory. To the best of our knowledge, this is the first time that the competence theory is applied in the field of crowdsourcing delivery. Besides, the developed MCCA approach provides a new approach to the competence analysis of personnel by considering the comprehensive impact of multicriteria from an MCDA perspective. As such, both the comprehensive competence analysis of crowdsourcing delivery personnel and the proposed MCCA approach enrich existing research in the areas of competence, crowdsourcing, and logistics.

(2) The MCCA approach builds a generic analysis framework to assess the competence of personnel, while the real-world case study provides a solid validation of its applicability. Furthermore, it is not limited to the area of crowdsourcing delivery: as long as the multiple criteria and corresponding scores for the personnel are determined within a specific working environment, the MCCA approach can always provide reasonable results, which means it can be used in other industries as well.

(3) Bayesian BWM serves as an effective tool for implementing the MCCA approach. Given the predetermined criteria in MCCA, it produces more colorful results that reflect the preferences of DMs and the relative relationships between the criteria from a probabilistic angle. For instance, if we look at the main dimensions of the proposed KSAT framework, "Skills" is the most important criterion, with a confidence of 1 over "Traits" and "Knowledge," in which case DMs' preference of a criterion could be confirmed explicitly with a certain confidence level.

\subsection{Managerial Implications}

(1) In the tailored MCCA framework, "Skills" is considered the most important and "Knowledge" is the least important, which indicates that it is important for managers to consider certain job skills, not only when hiring and promoting personnel, but also in terms of job training, entry setting, and postscreening for personnel. As for the dimension of "Knowledge," although it is considered the least important in this particular case, it may be more important in other scenarios. Moreover, there are four critical criteria identified from the 14 subcriteria, indicating that a comprehensive competence evaluation system needs to be established in which core elements need to be prioritized when analyzing the competence of the personnel involved.

(2) In the crowdsourcing delivery market, the delivery personnel consist of a large number of people with a complex composition and high level of mobility, creating enormous challenges for the management of a crowdsourcing platform. To keep the organization healthy, the managers have to develop standardized operating procedures, management systems, and incentive plans to retain personnel, including the use of ICT and social welfare policies. Also, the MCCA can be seen as a learning tool rather than as a mere grading system. It can help crowdsourcing delivery personnel understand their strengths and weaknesses and allow them to improve in areas where they are weaker, in a structured and targeted manner.

(3) How long crowdsourcing delivery personnel have been on the job has a significant impact on their competence level and stability. A comparison of the four groups shows that their competence levels improve over time, while more pronounced fluctuations reflect a shorter time on the job. At an individual level, this provides some indication that competence is an individual's accumulated performance in many aspects during a certain period, which means that every dimension in the proposed KSAT framework is indispensable when it comes to the development of competence. Meanwhile, it motivates platform managers to formulate attractive human resource policies, provide convenient equipment and facilities, and create a better working environment for the crowdsourcing delivery personnel, persuading them to stay and thus sustain the platform's long-term development.

6.3. Future Research. In this paper, we performed the competence analysis of crowdsourcing delivery personnel by using the data collected from Chongqing, while the sample size was also limited. Future research could collect more data from different regions, possibly integrating big data analysis techniques into the MCCA approach. Furthermore, the developed MCCA approach was illustrated by a real-world case study set within a specific crowdsourcing delivery scenario. There are other delivery modes as well, like dedicated delivery and merchant's taking care of the delivery themselves, and future studies could compare these different alternatives using the method set out in this paper. Finally, 
while we used additive value function as an aggregation method, there are alternative methods as well, including outranking methods, to aggregate the data being collected.

\section{Data Availability}

The data used in this paper consists of two parts. For the internal statistical data of the crowdsourcing delivery platform such as average delivery time, total delivery mileage, and customer ratings as well as the data obtained by conducting telephone interviews with crowdsourcing delivery personnel working on this platform such as total order quantity, registration time, and relevant work experience, they have not yet made available because these data belong to the right of a third party, the crowdsourcing delivery platform, so the authors can only use these data for academic research, but have no right to publish data sources. For another part of the data, the Bayesian BWM questionnaires that were sent to the site managers are available by sending an e-mail to the corresponding author atwx921@163.com.

\section{Conflicts of Interest}

The authors declare that there are no conflicts of interest regarding the publication of this paper.

\section{Acknowledgments}

The authors would like to thank Dr. Majid Mohammadi for his help in the process of revising this paper. They would like to thank Miss Fang Li for her help in data collection, the managers for answering questionnaires, and the crowdsourcing delivery personnel for taking part in their telephone interviews. This study was supported by the China Scholarship Council (Grant no. CSC201906050168) and National Key R\&D Project (Grant no. 2018YFB1403602).

\section{References}

[1] M. Savelsbergh and T. Van Woensel, "50th anniversary invited article-city logistics: challenges and opportunities," Transportation Science, vol. 50, no. 2, pp. 579-590, 2016.

[2] L. Li, X. Wang, Y. Lin, F. Zhou, and S. Chen, "Cooperative game-based profit allocation for joint distribution alliance under online shopping environment," Asia Pacific Journal of Marketing and Logistics, vol. 31, no. 2, pp. 302-326, 2019.

[3] S. Chandra, R. T. Naik, and J. Jimenez, "Crowdsourcing-based traffic simulation for smart freight mobility," Simulation Modelling Practice and Theory, vol. 95, pp. 1-15, 2019.

[4] N. Kafle, B. Zou, and J. Lin, "Design and modeling of a crowdsource-enabled system for urban parcel relay and delivery," Transportation Research Part B: Methodological, vol. 99, pp. 62-82, 2017.

[5] Y. Wang, D. Zhang, Q. Liu, F. Shen, and L. H. Lee, “Towards enhancing the last-mile delivery: an effective crowd-tasking model with scalable solutions," Transportation Research Part E: Logistics and Transportation Review, vol. 93, pp. 279-293, 2016.

[6] A. Giret, C. Carrascosa, V. Julian, M. Rebollo, and V. Botti, "A crowdsourcing approach for sustainable last mile delivery," Sustainability, vol. 10, no. 12, p. 4563, 2018.
[7] H. Paloheimo, M. Lettenmeier, and H. Waris, "Transport reduction by crowdsourced deliveries-a library case in Finland," Journal of Cleaner Production, vol. 132, pp. 240-251, 2016.

[8] L. Li, X. Wang, Y. Lin, K. Liu, and Y. Tang, "Network sharing based two-tier vehicle routing optimization of urban joint distribution under online shopping," in Recent Advances in Intelligent Manufacturing, pp. 131-145, Springer, Berlin, Germany, 2018.

[9] M. Basili and M. A. Rossi, "Platform-mediated reputation systems in the sharing economy and incentives to provide service quality: the case of ridesharing services," Electronic Commerce Research and Applications, vol. 39, p. 100835, 2020.

[10] J. Howe, "The rise of crowdsourcing," Wired Magazine, vol. 14, no. 6, pp. 1-4, 2006.

[11] X. Cheng, S. Fu, and G.-J. de Vreede, "A mixed method investigation of sharing economy driven car-hailing services: online and offline perspectives," International Journal of Information Management, vol. 41, pp. 57-64, 2018.

[12] A. Mladenow, C. Bauer, and C. Strauss, "“Crowd logistics": the contribution of social crowds in logistics activities," International Journal of Web Information Systems, vol. 12, no. 3, pp. 379-396, 2016.

[13] V. E. Castillo, J. E. Bell, W. J. Rose, and A. M. Rodrigues, "Crowdsourcing last mile delivery: strategic implications and future research directions," Journal of Business Logistics, vol. 39, no. 1, pp. 7-25, 2018.

[14] M. Mulder, "Conceptions of professional competence," in International Handbook of Research in Professional and Practice-Based Learning, S. Billett, C. Harteis, and H. Gruber, Eds., pp. 107-137, Springer, Berlin, Germany, 2014.

[15] P. Hager, A. Gonczi, and J. Athanasou, "General issues about assessment of competence," Assessment \& Evaluation in Higher Education, vol. 19, no. 1, pp. 3-16, 1994.

[16] L. B. Erickson and E. M. Trauth, "Getting work done: evaluating the potential of crowdsourcing as a model for business process outsourcing service delivery," in Proceedings of the 2013 Annual Conference on Computers and People Research, pp. 135-140, Kowloon, Hong Kong, March 2013.

[17] M. Dursun and E. E. Karsak, "A fuzzy MCDM approach for personnel selection," Expert Systems with Applications, vol. 37, no. 6, pp. 4324-4330, 2010.

[18] J. C. Correa, W. Garzón, P. Brooker et al., "Evaluation of collaborative consumption of food delivery services through web mining techniques," Journal of Retailing and Consumer Services, vol. 46, pp. 45-50, 2019.

[19] W. Zuo, W. Zhu, S. Chen, and X. He, "Service quality management of online car-hailing based on PCN in the sharing economy," Electronic Commerce Research and Applications, vol. 34, p. 100827, 2019.

[20] P.-E. Ellström and H. Kock, "Competence development in the workplace: concepts, strategies and effect," Asia Pacific Education Review, vol. 9, no. 1, pp. 5-20, 2008.

[21] H. B. Rai, S. Verlinde, J. Merckx, and C. Macharis, "Crowd logistics: an opportunity for more sustainable urban freight transport?" European Transport Research Review, vol. 9, no. 3, 2017.

[22] V. Carbone, A. Rouquet, and C. Roussat, "The rise of crowd logistics: a new way to Co-create logistics value," Journal of Business Logistics, vol. 38, no. 4, pp. 238-252, 2017.

[23] C. Bauer, A. Mladenow, and C. Strauss, "Fostering collaboration by location-based crowdsourcing," in Proceedings of the International Conference on Cooperative Design, Visualization 
and Engineering, Springer, Seattle, WA, USA, pp. 88-95, September 2014.

[24] M. K. Poetz and M. Schreier, "The value of crowdsourcing: can users really compete with professionals in generating new product ideas?" Journal of Product Innovation Management, vol. 29, no. 2, pp. 245-256, 2012.

[25] R. I. Meituan, Takeaway rider group research report-Meituan Research Institute, Meituan Research Institute, Jinan, China, 2018.

[26] A. Devari, A. G. Nikolaev, and Q. He, "Crowdsourcing the last mile delivery of online orders by exploiting the social networks of retail store customers," Transportation Research Part E: Logistics and Transportation Review, vol. 105, pp. 105-122, 2017.

[27] M. Behrend and F. Meisel, "The integration of item-sharing and crowdshipping: can collaborative consumption be pushed by delivering through the crowd?" Transportation Research Part B: Methodological, vol. 111, pp. 227-243, 2018.

[28] D. C. McClelland, "Testing for competence rather than for "intelligence."” American Psychologist, vol. 28, no. 1, p. 1, 1973.

[29] S. Messick, "Response to changing assessment needs: redesign of the national assessment of educational progress," ETS Research Report Series, vol. 1984, no. 2, 1984.

[30] A. Gonczi, P. Hager, and J. Athanasou, The Development of Competency-Based Assessment Strategies for the Professions, AGPS, Canberra, Australia, 1993.

[31] G. Beaumont, Review of 100 NVQs and SVQs: A Report Submitted to the Department for Education and Employment, Evaluation Advisory Group, Chesterfield, England, 1995.

[32] R. Kurz and D. Bartram, "Competency and individual performance: modelling the world of work," Organisational Effectiveness: The Role of Psychology, pp. 227-258, Wiley, Hoboken, NJ, USA, 2002.

[33] R. E. Boyatzis, The Competent Manager: A Model for Effective Performance, Wiley, Hoboken, NJ, USA, 1982.

[34] G. Cheetham and G. Chivers, "The reflective (and competent) practitioner: a model of professional competence which seeks to harmonise the reflective practitioner and competencebased approaches," Journal of European Industrial Training, vol. 22, no. 7, pp. 267-276, 1998.

[35] J. Winterton, "Entrepreneurship: towards a competence framework for developing SME managers," in United States Association for Small Business and Entrepreneurship Conference Proceedings, Boston, MA, USA, March 2002.

[36] F. D. Le Deist and J. Winterton, "What is competence?" Human Resource Development International, vol. 8, no. 1, pp. 27-46, 2005.

[37] T. J. Maurer and M. Lippstreu, "Expert vs. general working sample differences in KSAO improvability ratings and relationships with measures relevant to occupational and organizational psychology," Journal of Occupational and Organizational Psychology, vol. 81, no. 4, pp. 813-829, 2008.

[38] R. J. Shavelson, "On the measurement of competency," Empirical Research in Vocational Education and Training, vol. 2, no. 1, pp. 41-63, 2010.

[39] J. Martin, M. Elg, I. Gremyr, and A. Wallo, "Towards a quality management competence framework: exploring needed competencies in quality management," Total Quality Management \& Business Excellence, pp. 1-20, 2019.

[40] A. Gonczi, "Competency based assessment in the professions in Australia," Assessment in Education: Principles, Policy \& Practice, vol. 1, no. 1, pp. 27-44, 1994.
[41] V. Wass, C. Van der Vleuten, J. Shatzer, and R. Jones, "Assessment of clinical competence," The Lancet, vol. 357, no. 9260, pp. 945-949, 2001.

[42] G. E. Miller, "The assessment of clinical skills/competence/ performance," Academic Medicine, vol. 65, no. 9, pp. S63-S67, 1990.

[43] D. McRobbi, D. G. Webb, I. Bates, J. Wright, and J. G. Davies, "Assessment of clinical competence: designing a competence grid for junior pharmacists," Pharmacy Education, vol. 1, pp. 67-76, 2001.

[44] J. Hartig, E. Klieme, and D. Leutner, Assessment of Competencies in Educational Contexts, Hogrefe Publishing, Göttingen, Germany, 2008.

[45] R. Safadi, M. Jaradeh, A. Bandak, and E. Froelicher, "Competence assessment of nursing graduates of Jordanian universities," Nursing \& Health Sciences, vol. 12, no. 2, pp. 147-154, 2010.

[46] R. Nikolov, E. Shoikova, and E. Kovatcheva, Competence Based Framework For Curriculum Development, Vol. 18, Za Bukvite-O Pismeneh, Bulgaria, Sofia, 2014.

[47] X.-K. Wang, Y.-T. Wang, J.-Q. Wang, P.-F. Cheng, and L. Li, "A TODIM-PROMETHEE II based multi-criteria group decision making method for risk evaluation of water resource carrying capacity under probabilistic linguistic Z-number circumstances," Mathematics, vol. 8, no. 7, p. 1190, 2020.

[48] J.-j. Peng, C. Tian, W.-y. Zhang, S. Zhang, and J.-q. Wang, "An integrated multi-criteria decision-making framework for sustainable supplier selection under picture fuzzy environment," Technological and Economic Development of Economy, vol. 26, no. 3, pp. 573-598, 2020.

[49] W. Edwards, "How to use multiattribute utility measurement for social decisionmaking," IEEE Transactions on Systems, Man, and Cybernetics, vol. 7, no. 5, pp. 326-340, 1977.

[50] T. L. Saaty, "A scaling method for priorities in hierarchical structures," Journal of Mathematical Psychology, vol. 15, no. 3, pp. 234-281, 1977.

[51] T. L. Saaty, Decision Making with Dependence and Feedback: The Analytic Network Process, RWS Publications, Pittsburgh, PA, USA, 1996.

[52] J. Rezaei, "Best-worst multi-criteria decision-making method," Omega, vol. 53, pp. 49-57, 2015.

[53] R. Keeney and H. Raiffa, Decisions with Multiple Objectives: Preferences and Value Tradeoffs, Wiley, New York, NY, USA, 1976.

[54] J. Rezaei, "Best-worst multi-criteria decision-making method: some properties and a linear model," Omega, vol. 64, pp. 126-130, 2016.

[55] J. Rezaei, "A concentration ratio for nonlinear best worst method," International Journal of Information Technology \& Decision Making, vol. 19, no. 3, pp. 891-907, 2020.

[56] B. J. Adame, "Training in the mitigation of anchoring bias: a test of the consider-the-opposite strategy," Learning and Motivation, vol. 53, pp. 36-48, 2016.

[57] J. Rezaei, A. Hemmes, and L. Tavasszy, "Multi-criteria decision-making for complex bundling configurations in surface transportation of air freight," Journal of Air Transport Management, vol. 61, pp. 95-105, 2017.

[58] F. De Prieëlle, M. De Reuver, and J. Rezaei, "The role of ecosystem data governance in adoption of data platforms by internet-of-things data providers: case of Dutch horticulture industry," IEEE Transactions on Engineering Management, 2020.

[59] R.-x. Nie, Z.-p. Tian, J.-q. Wang, H.-y. Zhang, and T.-l. Wang, "Water security sustainability evaluation: applying a 
multistage decision support framework in industrial region," Journal of Cleaner Production, vol. 196, pp. 1681-1704, 2018.

[60] S. Kheybari, F. M. Rezaie, and J. Rezaei, "Measuring the importance of decision-making criteria in biofuel production technology selection," IEEE Transactions on Engineering Management, 2019.

[61] M. S. Kaswan and R. Rathi, "Investigating the enablers associated with implementation of green lean six sigma in manufacturing sector using best worst method," Clean Technologies And Environmental Policy, vol. 22, pp. 1-12, 2020.

[62] M. O. M. Javad, M. Darvishi, and A. O. M. Javad, "Green supplier selection for the steel industry using BWM and fuzzy TOPSIS: a case study of Khouzestan steel company," Sustainable Futures, vol. 2, 2020.

[63] A. Kumar and H. Gupta, "Evaluating green performance of the airports using hybrid BWM and VIKOR methodology," Tourism Management, vol. 76, p. 103941, 2020.

[64] X. Mi, M. Tang, H. Liao, W. Shen, and B. Lev, "The state-ofthe-art survey on integrations and applications of the best worst method in decision making: why, what, what for and what's next?" Omega, vol. 87, pp. 205-225, 2019.

[65] M. Mohammadi and J. Rezaei, "Bayesian best-worst method: a probabilistic group decision making model," Omega, vol. 96, p. 102075, 2020.

[66] M. Brunelli and J. Rezaei, "A multiplicative best-worst method for multi-criteria decision making," Operations Research Letters, vol. 47, no. 1, pp. 12-15, 2019.

[67] C. Forbes, M. Evans, N. Hastings, and B. Peacock, Statistical Distributions, Wiley, Hoboken, NJ, USA, 2011.

[68] M. Mohammadi and J. Rezaei, "Evaluating and comparing ontology alignment systems: an MCDM approach," Journal of Web Semantics, vol. 64, p. 100592, 2020.

[69] E. T. Jaynes, "Information theory and statistical mechanics," Physical Review, vol. 106, no. 4, p. 620, 1957.

[70] S. Richardson and D. J. Spiegelhalter, Markov Chain Monte Carlo In Practice, Taylor \& Francis, Milton Park, UK, 1995.

[71] M. Plummer, JAGS: Just Another Gibbs Sampler, American Educational Research Association, Washington, DC, USA, 2004.

[72] M. Eraut, "Concepts of competence," Journal of Interprofessional Care, vol. 12, no. 2, pp. 127-139, 1998.

[73] M. Aghaee and R. Aghaee, "Selection of logistics personnel by using and hybrid fuzzy DEMATEL and fuzzy ANP," International Research Journal of Management Sciences, vol. 4, no. 1, pp. 14-22, 2016.

[74] M. Kabak, S. Burmaoğlu, and Y. Kazançoğlu, "A fuzzy hybrid MCDM approach for professional selection,” Expert Systems with Applications, vol. 39, no. 3, pp. 3516-3525, 2012.

[75] J. Rezaei, J. Wang, and L. Tavasszy, "Linking supplier development to supplier segmentation using Best Worst Method," Expert Systems with Applications, vol. 42, no. 23, pp. 9152-9164, 2015.

[76] D. Bowersox, D. Closs, and M. Cooper, Supply Chain Logistics Management, McGraw Hill, New York, NY, USA, 2002. 